\title{
Hepatitis B Response of Premature Infants after Primary and Booster Immunisation with a Diphtheria-Tetanus-Acellular Pertussis-Hepatitis B-Inactivated Poliovirus/Haemophilus Influenzae Type B Vaccine
}

\author{
Felix Omeñaca, ${ }^{1}$ Jose Garcia-Sicilia, ${ }^{2}$ Reyes Boceta, ${ }^{3}$ and Pilar García-Corbeira ${ }^{3}$ \\ ${ }^{1}$ Neonatal Unit, Department of Neonatology, La Paz Hospital, Castellana 261, 28046 Madrid, Spain \\ ${ }^{2}$ Department of Paediatrics, La Paz Hospital, 28046 Madrid, Spain \\ ${ }^{3}$ Medical Department, GlaxoSmithKline, Tres Cantos, Madrid, Spain
}

Correspondence should be addressed to Felix Omeñaca, fomenaca.hulp@salud.madrid.org

Received 1 December 2009; Accepted 4 March 2010

Academic Editor: José Tirán-Saucedo

Copyright ( 2010 Felix Omeñaca et al. This is an open access article distributed under the Creative Commons Attribution License, which permits unrestricted use, distribution, and reproduction in any medium, provided the original work is properly cited.

\begin{abstract}
A range of schedules are recommended for hepatitis B vaccination of premature infants. This open-label study (217744/083) compared the immune response of premature $(N=94)$ and full-term infants $(N=92)$ to hepatitis $\mathrm{B}$ antigen following primary administration of hexavalent DTPa-HBV-IPV/Hib vaccine at 2-4-6 months and a booster dose at 18 months. AntiHBsAg antibodies were determined before and one month after primary and booster doses. There were no significant differences in postprimary seroprotection rates (anti-HBsAg $>10 \mathrm{mIU} / \mathrm{mL}$; preterm 93.4\%; full-term $95.2 \%$ ) or geometric mean concentrations (634 versus $867 \mathrm{mIU} / \mathrm{ml}$ ), and neither appeared to be related to gestational length or birth weight. Prebooster seroprotection rates were 75 and $80.6 \%$, respectively. Six premature infants did not respond to primary and booster doses. Primary and booster vaccinations with DTPa-HBV-IPV/Hib elicit satisfactory anti-HBsAg responses in preterm infants, which are not influenced by gestational age or birth weight. This schedule and vaccine will greatly facilitate the immunisation of premature infants.
\end{abstract}

\section{Introduction}

Infection with hepatitis B virus (HBV) persists as a worldwide public health problem, with vertical transmission of HBV being responsible for approximately one third of all new cases of hepatitis B. Childhood hepatitis B immunisation has significantly reduced the incidence and prevalence of HBV infection [1], and currently more than 160 countries use hepatitis $B$ vaccine in their national immunisation programmes. Exciting new global initiatives have been implemented that allow the poorest countries in the world to afford this vaccine [2].

The number of infants born prematurely has risen in the last 15 years, and recent advances in the care of premature infants have substantially increased their survival rates [3]. It is now thought that prematurity, rather than a specific gestational age or birth weight, is more predictive of immunologic HBV response compared with full-term infants. The latest recommendation is that medically stable preterm or low-birth weight babies (weighing $>2000 \mathrm{~g}$ ) who are born to hepatitis B surface antigen ( $\mathrm{HBsAg}$ ) negative mothers should receive HBV at birth or shortly thereafter. [4].

Concern among parents and paediatricians about the number of injections required during each immunisation visit has contributed to the observation that routine paediatric vaccination is often delayed in preterm infants $[5,6]$. However, several combined vaccines are now available which reduce the required number of injections and medical visits. The acceptability of multiple immunisations and increasing the coverage of each vaccine can thereby be achieved.

We have previously shown preterm infants less than 37 weeks of gestational age to display satisfactory immune response to all component antigens of a hexavalent 
diphtheria-tetanus-acellular pertussis-hepatitis B-inactivated poliovirus-Haemophilus influenzae type $\mathrm{B}$ vaccine (DTPa-HBV-IPV/Hib), with seroprotection/vaccine response rates generally similar to those seen in full-term infants following primary vaccination and a booster dose [7-9]. This paper details the results of a further analysis of the immune response in the preterm cohort to the hepatitis $B$ component of this hexavalent vaccine, including a follow-up at 18 months and a specific focus on the nonresponders.

\section{Materials and Methods}

2.1. Study Design. This was an open-label study with two parallel groups: preterm subjects ( $<37$ weeks' gestation) and a control group of full-term infants. The study protocol was approved by the Clinical Investigation Research Board of La Paz Hospital and conducted in accordance with Good Clinical Practice Guidelines. Written informed consent was obtained from the parents or guardians of all subjects prior to enrolment. Trial number: 217744/083 (DTPa-HBV-IPV083).

2.2. Subjects. Preterm subjects were stratified according to clinical characteristics including length of gestation, birth weight, pre- and postnatal steroid use, need for red blood cell transfusion, and weight at 6 months. Length of gestation was determined by date of the last menstrual period and/or early ultrasound scan and subsequently confirmed by neonatal examination. Exclusion criteria comprised major congenital defects or serious chronic illnesses, severe neurologic damage or nontreatable convulsions; known or suspected immune dysfunction, HIV positive or hepatitis B surface antigen (HBsAg) positive mother, acute disease or rectal temperature $\geq 38^{\circ} \mathrm{C}$ (immunization deferred), a history of allergic reaction to any of the vaccine components, apnea episode within 7 days of vaccination, steroid therapy 30 days before the first vaccine dose, any immunoglobulin therapy within 2 months before enrollment or during the trial, administration of any vaccine or experimental drug or vaccine during the 30 days after/before the administration of the study vaccine.

2.3. Vaccines. All subjects were primed with a DTPa-HBVIPV/Hib vaccine [Infanrix hexa, GlaxoSmithKline (GSK) Biologicals, Rixensart, Belgium] at 2, 4, and 6 months and received a booster dose with the same vaccine at 18 months of age. The vaccine was administered as a $0.5 \mathrm{~mL}$ intramuscular injection into the right anterolateral thigh.

Each dose of DTPa-HBV-IPV/Hib vaccine contained $\geq 30$ international units (IU) of diphtheria toxoid, $\geq 40 \mathrm{IU}$ of tetanus toxoid, $25 \mu \mathrm{g}$ of adsorbed pertussis toxin, $25 \mu \mathrm{g}$ of adsorbed filamentous hemagglutinin, $8 \mu \mathrm{g}$ of adsorbed pertactin, $10 \mu \mathrm{g}$ of HBsAg, 40, 8, and $32 \mathrm{D}$-antigen units of polio virus types 1,2 , and 3 , respectively, and $0.7 \mathrm{mg}$ of aluminum as salts. The lyophilized Hib vaccine pellet contained $10 \mu \mathrm{g}$ of Haemophilus influenzae type b polysaccharide conjugated to 20 to $40 \mu \mathrm{g}$ of tetanus toxoid, $0.12 \mathrm{mg}$ of aluminium phosphate, and $10 \mathrm{mg}$ of lactose.
For infants not responding to primary and booster doses (anti-HBs $<10 \mathrm{mIU} / \mathrm{mL}$ ), three further $10 \mu \mathrm{g}$ doses of hepatitis B recombinant vaccine (Engerix-B; GSK Biologicals) could be administered in the third year of life. If the anti-HBs titre was above $100 \mathrm{mIU} / \mathrm{mL}$ after the second additional dose (6th in total), then the third dose was not given. If it was below $100 \mathrm{mIU} / \mathrm{mL}$, then the third dose was administered.

2.4. Immunogenicity Analysis. Blood samples were drawn before the first dose and one month after the third in primary course and before and one month after the booster dose. Serum samples were stored at $-20^{\circ} \mathrm{C}$ until analysis at GSK Biologicals. Antibodies against HBV were determined using ELISA (enzyme-linked immunosorbent assay), with an assay cut-off of $10 \mathrm{mIU} / \mathrm{mL}$ for HBsAg.

2.5. Statistical Analysis. Statistical analysis of the immunogenicity results was performed on the according-to-protocol (ATP) cohort. Seroprotection rates and antibody geometric mean concentrations (GMCs) were calculated with exact $95 \%$ confidence intervals (CI) at each time point. Differences in seroprotection rates between the preterm and full-term groups were compared using Fisher's exact test.

\section{Results}

A total of 186 infants were enrolled ( 94 preterm and 92 fullterm), of whom 93 and 89 infants, respectively complied with the criteria for inclusion in the ATP cohort for analysis of immunogenicity of the primary vaccination course. The demographic and neonatal characteristics of the infants have been previously described [7]. The mean age at the time of first immunisation was $8.6 \pm 0.63$ weeks (range $8-11$ weeks) and $8.2 \pm 0.8$ (range 6-11 weeks), respectively.

Of the 155 infants who received booster doses, 152 subjects were included in the ATP cohort for analysis of immunogenicity of the booster dose (84 prematurely born subjects and 68 full-term subjects). Mean age at the time of booster vaccination was $18.2 \pm 0.47$ months (range 1820 months) and $18.3 \pm 0.55$ months (range 18-20 months), respectively.

3.1. Postprimary Immunogenicity Results. The mean immunogenicity data after primary course and before and after booster dose are included in Table 1. A total of $93.4 \%$ of the preterm and $95.2 \%$ of the full-term infants responded to primary vaccination (anti-HBs $\geq 10 \mathrm{mIU} / \mathrm{mL}$ ). Although the GMCs after the primary course were numerically lower in the preterm group, the differences were not significant.

The immunogenicity results by gestational age are shown in Table 2. All subjects with a gestation below 31 weeks were seroprotected compared with $83.3 \%$ and $92.6 \%$ in the groups with a higher gestational age. However, with respect to GMCs, a numerically higher response was seen in the groups aged 34-36 weeks and 28-30 weeks but the differences were not significantly different. After the booster dose, the seroprotection rates were lower for the groups with 
TABLE 1: Anti- HBs seroprotection rates and GMCs in preterm and full-term infants one month after the primary course and before and after the booster dose (ATP cohort for immunogenicity).

\begin{tabular}{|c|c|c|c|c|c|c|}
\hline & \multirow[b]{2}{*}{$N$} & \multicolumn{3}{|c|}{ Seroprotection } & \multicolumn{2}{|c|}{ GMC } \\
\hline & & $n$ & $\%$ & $95 \%$ CI & $\mathrm{mIU} / \mathrm{ml}$ & $95 \% \mathrm{CI}$ \\
\hline \multicolumn{7}{|c|}{ Postprimary } \\
\hline Preterm & 91 & 85 & 93.4 & $86.2-97.5$ & 634.1 & $433.8-927.0$ \\
\hline Full-term & 84 & 80 & 95.2 & $88.3-98.7$ & 867.1 & $576.6-1303.9$ \\
\hline \multicolumn{7}{|c|}{ Prebooster } \\
\hline Preterm & 84 & 63 & 75.0 & $64.4-83.8$ & 56.8 & $39.6-81.4$ \\
\hline Full-term & 67 & 54 & 80.6 & $69.1-89.2$ & 58.1 & $39.1-86.3$ \\
\hline \multicolumn{7}{|c|}{ Postbooster } \\
\hline Preterm & 83 & 76 & 91.6 & $83.4-96.5$ & 1771.0 & $1060.3-2958.1$ \\
\hline Full-term & 68 & 67 & 98.5 & $92.1-100.0$ & 1965.0 & $1180.1-3272.0$ \\
\hline
\end{tabular}

TABLE 2: Anti-HBs seroprotection rates (SR) and geometric mean concentrations (GMC) by subgroup of preterm infants after primary course and booster dose (ATP cohort for immunogenicity).

\begin{tabular}{|c|c|c|c|c|c|c|}
\hline \multirow[b]{2}{*}{ Gestational age (weeks) } & \multirow[b]{2}{*}{$N$} & \multicolumn{3}{|c|}{ Seroprotection } & \multicolumn{2}{|c|}{ GMC } \\
\hline & & $n$ & $\%$ & $95 \% \mathrm{CI}$ & $\mathrm{mIU} / \mathrm{ml}$ & $95 \% \mathrm{CI}$ \\
\hline \multicolumn{7}{|c|}{ Primary course } \\
\hline $34-36$ & 27 & 25 & 92.6 & 75.7-99.1 & 955.9 & $461.1-1981.8$ \\
\hline $31-33$ & 24 & 20 & 83.3 & $62.6-95.3$ & 418.0 & $153.7-1136.4$ \\
\hline $28-30$ & 20 & 20 & 100 & $83.2-100$ & 1044.5 & $633.9-1721$ \\
\hline $24-27$ & 20 & 20 & 100 & $83.2-100$ & 364.8 & $184.5-721.5$ \\
\hline \multicolumn{7}{|c|}{ Booster dose } \\
\hline $34-36$ & 24 & 22 & 91.7 & $73.0-99.0$ & 2389.1 & 919.4-6207.9 \\
\hline $31-33$ & 23 & 18 & 78.3 & $56.3-92.5$ & 1127.2 & $262.2-4845.2$ \\
\hline $28-30$ & 18 & 18 & 100 & $81.5-100$ & 3555.9 & $1881.1-6721.8$ \\
\hline $24-27$ & 18 & 18 & 100 & $81.5-100$ & 1054.0 & $508.6-2184.2$ \\
\hline
\end{tabular}

higher gestational age but GMCs retained a similar pattern to that observed after the primary course.

A nonconsistent response was also seen in the analysis according to birth weight (Table 3), where $92 \%$ of subjects with the lowest birth weight were protected compared with all babies with birth weight 1000-1500g. Only $82.4 \%$ of those weighing more than $2000 \mathrm{~g}$ at birth were seroprotected. No specific pattern of GMC response was observed. Similarly, there was no significant difference according to babies with $(N=15)$ or without $(N=76)$ intrauterine growth restriction (seroprotection rates: 86.6 and $94.7 \%$, resp.), or with $(N=$ $67)$ or without $(N=24)$ prenatal steroids (seroprotection rates: 91 and $100 \%$, resp.).

Post-primary anti-HBs seroprotection rates and GMCs were numerically lower in the nine subjects who had received postnatal steroids $(88.9 \%$ and 188.1 , resp.) than the 81 subjects who had not received them (93.9\% and 724.6 , resp.), but the differences were not significant.

Blood transfusion during the neonatal period did not significantly affect seroprotection rates (anti-HBs $\geq 10$ $\mathrm{mIU} / \mathrm{mL}$ ) or GMCs [transfused infants: $94.7 \%$ (95\% CI 82.3-99.4) and 486.6 (95\% CI 280.0-845.5) $\mathrm{mIU} / \mathrm{ml}$, respectively; no transfusion: $92 \%(95 \% \mathrm{CI} 81.8-97.9)$ and 766.8 (95\% CI 542.8-1298.7) $\mathrm{mIU} / \mathrm{mL}$, resp.) in all babies.
Considering weight at 2 and 6 months as a variable independent of gestational age and birth weight, no significant patterns of differences were observed in seroprotection rates (Table 4).

3.2. Prebooster Persistence and Booster Response. Before the booster dose, both the seroprotection rates of anti-HBs GMCs were low in both the pre- and full-term groups (Table 1). Seroprotection rose to 91.6 and $98.5 \%$, respectively one month after the booster dose and the GMCs increased to 1771 and $1965 \mathrm{mIU} / \mathrm{mL}$, respectively. There were no significant differences between the responses in the preterm and full-term groups.

3.3. Nonresponders. Six preterm infants $(6.59 \%)$ did not respond to primary immunisation and also failed to respond to the booster dose (anti-HBs $\geq 10 \mathrm{mIU} / \mathrm{mL}$; Table 5). All of these infants had a gestational age above 31 weeks. Two babies weighed less than $1000 \mathrm{~g}$ at birth and had severe intrauterine growth restriction (IUGR; 32 weeks/600 g and 31 weeks/800 g), but the other four babies did not have any risk factors.

One infant responded to the 5th HBV dose, two to the 6 th, and one to the 7 th. Two babies (2.19\%) never responded. 
TABLE 3: Post-primary anti-HBs seroprotection rates and GMCs by birth weight (ATP cohort for immunogenicity).

\begin{tabular}{|c|c|c|c|c|c|c|}
\hline \multirow[b]{2}{*}{ Birth weight $(\mathrm{kg})$} & \multirow[b]{2}{*}{$N$} & \multicolumn{3}{|c|}{ Seroprotection } & \multicolumn{2}{|c|}{ GMC } \\
\hline & & $n$ & $\%$ & $95 \% \mathrm{CI}$ & $\mathrm{mIU} / \mathrm{ml}$ & $95 \% \mathrm{CI}$ \\
\hline$\geq 2.0$ & 17 & 14 & 82.4 & $156.6-96.2$ & 493.9 & $147.2-1657.0$ \\
\hline$\geq 1.5<2.0$ & 23 & 22 & 95.7 & $78.1-99.9$ & 933.8 & $418.8-2081.8$ \\
\hline$\geq 1.0<1.5$ & 26 & 26 & 100 & $86.8-100$ & 1294.5 & $882.5-1898.6$ \\
\hline$<1.0$ & 25 & 23 & 92.0 & $74.0-99.0$ & 250.7 & $122.0-515.1$ \\
\hline
\end{tabular}

TABLE 4: Post-primary anti-HBs seroprotection rates and GMCs by weight at vaccination and percentile weight at six months (ATP cohort for immunogenicity).

\begin{tabular}{|c|c|c|c|c|c|c|}
\hline & \multirow[b]{2}{*}{$N$} & \multicolumn{3}{|c|}{ Seroprotection } & \multicolumn{2}{|c|}{ GMC } \\
\hline & & $n$ & $\%$ & $95 \% \mathrm{CI}$ & $\mathrm{mIU} / \mathrm{ml}$ & $95 \% \mathrm{CI}$ \\
\hline \multicolumn{7}{|c|}{ Weight at first vaccination $(\mathrm{kg})$} \\
\hline$\geq 4$ & 19 & 16 & 84.2 & $60.4-96.6$ & 617.4 & $206.8-1843.8$ \\
\hline$\geq 3<4$ & 26 & 25 & 96.2 & $80.4-99.9$ & 984.0 & $479.0-2021.6$ \\
\hline$\geq 2<3$ & 26 & 26 & 100 & $86.8-100$ & 972.6 & $589.2-1605.3$ \\
\hline$<2$ & 20 & 18 & 90.0 & $68.3-98.8$ & 210.7 & $95.4-465.2$ \\
\hline \multicolumn{7}{|c|}{ Percentile weight at six months } \\
\hline$>50$ & 29 & 27 & 93.1 & $77.2-99.2$ & 1140.8 & $577.6-2253.1$ \\
\hline$>25 \leq 50$ & 21 & 20 & 95.2 & $76.2-99.9$ & 353.7 & $150.8-829.4$ \\
\hline$>10 \leq 25$ & 14 & 13 & 92.9 & $66.1-99.8$ & 561.4 & $205.7-1532.4$ \\
\hline$\leq 10$ & 27 & 25 & 92.6 & 75.7-99.1 & 566.2 & $280.0-1144.7$ \\
\hline
\end{tabular}

TABle 5: Anti-HBs concentrations $(\mathrm{mIU} / \mathrm{ml})$ after all HBV doses in subjects who were non-responders to hepatitis B at the end of the primary and booster studies.

\begin{tabular}{|c|c|c|c|c|c|c|c|c|c|c|c|c|c|}
\hline & & & & & & & & & & Post & Extra & HBV & HBV \\
\hline $\begin{array}{l}\text { Gestational } \\
\text { age (Weeks) }\end{array}$ & $\begin{array}{l}\text { Birth } \\
\text { weight } \\
(\mathrm{kg})\end{array}$ & $\begin{array}{l}\text { Percentile } \\
\text { at birth }\end{array}$ & $\begin{array}{c}\text { Weight at 1st } \\
\text { vaccination } \\
(\mathrm{kg})\end{array}$ & $\begin{array}{l}\text { Percentile } \\
\text { at } 6 \\
\text { months }\end{array}$ & $\begin{array}{c}\text { Weight at } \\
6 \text { months } \\
(\mathrm{kg})\end{array}$ & $\begin{array}{c}\text { Pre- } \\
\text { primary }\end{array}$ & $\begin{array}{c}\text { Post- } \\
\text { primary }\end{array}$ & $\begin{array}{c}\text { Pre- } \\
\text { booster }\end{array}$ & $\begin{array}{c}\text { Post- } \\
\text { booster }\end{array}$ & $\begin{array}{c}\text { Dose } \\
1\end{array}$ & $\begin{array}{c}\text { Dose } \\
2\end{array}$ & $\begin{array}{c}\text { Dose } \\
3\end{array}$ & $\begin{array}{c}\text { Persistence } \\
\text { at } 4 \text { years } \\
(\mathrm{mIU} / \mathrm{ml})\end{array}$ \\
\hline 33 & 2.1 & 75 & 4.4 & 95 & 8.3 & $<10$ & $<10$ & $<10$ & $<10$ & 690 & 3485 & NG & 176 \\
\hline 35 & 2.0 & 25 & 4 & 25 & 6.7 & $<10$ & $<10$ & $<10$ & $<10$ & $<10$ & $<10$ & 32 & 128 \\
\hline 32 & 0.6 & $<10$ & 1.7 & $<5$ & 4.4 & $<10$ & $<10$ & $<10$ & $<10$ & $<10$ & 141 & NG & 64 \\
\hline 31 & 0.8 & $<10$ & 1.7 & 10 & 5.1 & 97 & $<10$ & $<10$ & $<10$ & $<10$ & NA & NG & $<10$ \\
\hline 33 & 2.0 & 50 & 4.3 & $>90$ & 8.4 & $<10$ & $<10$ & $<10$ & $<10$ & $<10$ & $<10$ & $<10$ & $<10$ \\
\hline 35 & 1.7 & 10 & 3.6 & 50 & 6.6 & $<10$ & $<10$ & $<10$ & $<10$ & $<10$ & 1087 & NG & NA \\
\hline
\end{tabular}

$\mathrm{NA}=$ Not available; $\mathrm{NG}=$ Not given .

One was an infant with IUGR who had anti-HBs antibodies before vaccination and the other although born prematurely at 33 weeks weighed $2000 \mathrm{~g}$ and did not have risk factors. These 6 infants did show a good response to the other antigens included in the DTPa-HBV-IPV/Hib vaccine.

\section{Discussion}

The American Academy of Pediatrics (AAP) recommends that all infants receive hepatitis $B$ vaccine at birth or before discharge from the hospital. In infants weighing less than $2000 \mathrm{~g}$ and born to HbsAg negative mothers, the first dose of hepatitis B vaccine is recommended at 30 days [4].
Immunogenicity studies indicate that premature children generally respond less well to hepatitis B vaccination than full-term infants, both in terms of seroprotection rates [1015] and GMCs [14, 16-21]. Our results are consistent with these findings, although the seroprotection rate in preterm subjects was not significantly different to that in full-term subjects.

Analysis according to birth weight in premature infants has suggested a relationship between reduced immunological response and low birth weight $[16,20,22,23]$. Interestingly, in our study, babies under $1000 \mathrm{~g}$ achieved higher seroprotection rates than those children with a birth weight in excess of $2000 \mathrm{~g}$, but their GMC response was lower. 
Gestational age seems to be a much more objective parameter than weight for assessing immune response in premature babies. After birth dosing, both seroprotection rates and GMCs are generally lower in babies with a reduced gestational age $[16,20,21,23]$ but this trend reverses as the chronological age at the time of starting vaccination increases [24]. In our study, all children with a gestational age below 31 weeks responded to immunisation in the two groups with a greater gestational age. The response in terms of GMCs was however irregular.

Our findings strengthen the notion that the immunological response in premature babies depends on postnatal age of vaccination and not on birth weight or gestational age. Indeed, studies in term infants have demonstrated that very young infants (up to 2 months) achieve lower GMCs after three doses of hepatitis B vaccine compared to infants who are at least 3 months of age at the time of first vaccination [25].

Low-birth weight has been reported to be associated with an inadequate immune response to early hepatitis $B$ vaccination in premature infants by some workers [16], but others have either shown no effect [19] or the opposite [26]. Similar anomalies have been seen when considering gestational age $[19,26]$ and the postnatal use of corticosteroids $[16,26,27]$. In our study all of the nonresponders had a gestational age of at least 31 weeks and, except for two babies with severe IUGR, were of appropriate weight. Nine infants received postnatal corticosteroids and although they responded to a lesser extent to hepatitis $B$ vaccination, the differences were not significant. Only one of these babies was a non-responder. Two children in our cohort received transfusions (1 or 6) in the neonatal period, coinciding with severe intrauterine restriction, but no differences in response were identified between the transfused and nontransfused infants.

Other factors linked to nonresponse to hepatitis B vaccination in premature babies include hyperbilirubinaemia [28], sepsis $[16,19,26]$, and the presence of specific antibodies transferred by the mother through the placenta. All of the children in our study who did not respond to HBsAg developed jaundice, but all were within physiological limits for bilirubin. Sepsis was recorded in only one of the infants classified as a non-responder. Only one of our non-responding babies had prior antibodies, but in conjunction with severe intrauterine restriction and the receipt of multiple transfusions.

We found no differences in immune response in the infants with either IUGR, or in the different groups stratified according to percentile weight at 6 months, consistent with previous findings $[15,17]$. However, at the time of vaccine initiation, GMCs were lower in those children who weighed less than $2 \mathrm{~kg}$ but this is logical given that they were smaller at birth.

Three doses of HB vaccines are generally recommended in preterm babies, although 4 doses have been suggested $[10,15,17,22,29,30]$, as well as an antibody test after the third to assess the suitability of a booster dose $[19,20,22]$. In a study of 29 preterm infants who were non-responders, 14 received additional doses of vaccine; 7 seroconverted after the first additional dose, 3 required a second additional dose and 1 required a third [16]. In another study although only three of the nine non-responding pre-term infants returned for a fourth vaccine dose, all subsequently seroconverted [26]. We decided to administer 4 doses, but according to the schedule recommended for full-term babies, and include a booster dose at 18 months with the hexavalent vaccine used for primary vaccination. All six infants that did not respond to the primary course also did not respond to a fourth dose; 1 infant responded to the fifth, 2 to the sixth, and 1 after seven doses. Only two infants remained non-responders.

Few authors have studied the persistence of anti-HBs in premature infants; however, Kesler et al. [27] reported that similar declines in antibody titres are seen in pre-term and full-term babies after primary vaccination, although preterm infants generally have a lower titre. We found similar results prior to the booster dose and observed a good immune response with similar GMCs among preterm and full-term infants after the booster.

Many long-term studies of infants indicate that immunisation against hepatitis B induces both antibody-producingcells and memory cells, and the rapid development of anamnestic responses [31]. Booster doses of vaccine do not seem necessary to ensure long-term protection [3234], although some factors might be important. Delaying vaccination until infants achieve a weight of $2000 \mathrm{~g}$ results in a significantly higher GMC at 3-3.5 year of age as compared to early vaccination in both pre- and full-term infants [35]. Most children vaccinated at birth retain immunological memory to hepatitis B vaccine for 15 years, but those who did not were more likely to have received HB IG immunoglobulin at birth, suggesting that passive antibody may interfere with the induction of immunological memory [36].

In summary, preterm babies born to HBsAg-negative mothers and vaccinated with a hexavalent DTPa-HBVIPV/Hib vaccine at 2, 4, and 6 months responded well immunologically and similarly to children born at full term. The response in terms of seroprotection rates was not influenced either by gestational age or birth weight, and these findings strengthen the notion that the immunological response in premature babies depends on postnatal age and not on birth weight or gestational age. Six infants, all with a gestation age above 31 weeks, did not respond, but we did not find any associated risk factors, other than severe intrauterine malnutrition in two babies. After a further vaccination cycle, only 2 remained "true" non-responders. The vaccination schedule used here for preterm babies born to HBsAg-negative mothers offers a single schedule for all infants, with fewer injections and better acceptance.

\section{Acknowledgments}

The authors would like to thank the parents and children who participated in the study and the study nurses $\mathrm{M}^{\mathrm{a}}$ Cruz Morales, Carmen Ndongo, Marisa Prieto, and María José Ramiro, without whom this study would not have been possible. This study was supported by a grant from 
GlaxoSmithKline SA, Tres Cantos, Madrid, Spain. The authors would like to acknowledge Julia Donnelly (GSK, Rixensart) for technical assistance during the preparation of this manuscript. Infanrix Hexa and Engerix-B are trademarks of the GlaxoSmithKline group of companies.

\section{References}

[1] C. W. Shepard, L. Finelli, A. E. Fiore, and B. P. Bell, "Epidemiology of hepatitis B and hepatitis B virus infection in United States children," Pediatric Infectious Disease Journal, vol. 24, no. 9, pp. 755-760, 2005.

[2] E. Mast, F. Mahoney, M. Kane, and H. Margolis, "Hepatitis B vaccine," in Vaccines, S. A. Plotkin and W. A. Orenstein, Eds., pp. 299-337, Elsevier, Philadelphia, Pa, USA, 2004.

[3] M. M. Slattery and J. J. Morrison, "Preterm delivery," The Lancet, vol. 360, no. 9344, pp. 1489-1497, 2002.

[4] American Academy of Pediatrics, "Immunization in special clinical circumstances," in Red Book: 2003. Report of the Committee on Infectious Diseases, L. K. Pickering, Ed., pp. 6668, American Academy of Pediatrics, Elk Grove Village, Ill, USA, 26th edition, 2003.

[5] D. L. Langkamp, S. Hoshaw-Woodard, M. E. Boye, and S. Lemeshow, "Delays in receipt of immunizations in low-birthweight children: a nationally representative sample," Archives of Pediatrics and Adolescent Medicine, vol. 155, no. 2, pp. 167172,2001

[6] P. A. Offit, J. Quarles, M. A. Gerber, et al., 'Addressing parents' concerns: do multiple vaccines overwhelm or weaken the infant's immune system?" Pediatrics, vol. 109, no. 1, pp. 124129, 2002.

[7] F. Omeñaca, J. Garcia-Sicilia, P. Garcia-Corbeira, et al., "Response of preterm newborns to immunization with a hexavalent diphtheria-tetanus-acellular pertussis-hepatitis B virus-inactivated polio and Haemophilus influenzae type $b$ vaccine: first experiences and solutions to a serious and sensitive issue," Pediatrics, vol. 116, no. 6, pp. 1292-1298, 2005.

[8] F. Omeñaca, J. Garcia-Sicilia, P. Garcia-Corbeira, et al., "Immunogenicity of a combined DTPa-HBV-IPV/Hib hexavalent vaccine in preterm infants after primary and booster doses," in Proceedings of the 43th ICAAC Meeting, Chicago, Ill, USA, November 2003, abstract no. L-186A.

[9] F. Omeñaca, J. Garcia-Sicilia, P. Garcia-Corbeira, R. Boceta, and V. Torres, "Anti-PRP response of premature infants to primary and booster vaccination with a combined diphteriatetanus-acellular pertussis-hepatitis B-inactiavted polio virus /Haemophilus influenzae type b vaccine," Pediatrics, vol. 119, pp. e179-e185, 2007.

[10] P. Lumbiganon, P. Kowsuwan, P. Lumbiganon, S. Taksaphan, M. Panamonta, and A. Assateerawatts, "Comparison of immunogenicity of hepatitis B vaccine between low and normal birth weight infants," Asian Pacific Journal of Allergy and Immunology, vol. 10, no. 1, pp. 61-63, 1992.

[11] D. M. Patel, J. Butler, S. Feldman, G. R. Graves, and P. G. Rhodes, "Immunogenicity of hepatitis B vaccine in healthy very low birth weight infants," Journal of Pediatrics, vol. 131, no. 4, pp. 641-643, 1997.

[12] A. Belson, S. Reif, Y. Peled, and Y. Bujanover, "Immune response to hepatitis B virus vaccine in 1-year-old preterm and term infants," Journal of Pediatric Gastroenterology and Nutrition, vol. 23, no. 3, pp. 252-255, 1996.

[13] L. S. R. Sadeck and J. L. A. Ramos, "Immune response of preterm infnats to hepatitis B vaccine administerd within 24 hours after birth," Journal of Pediatrics, vol. 80, pp. 113-118, 2004.

[14] M. Soares, M. M. Mussi-Pinhata, S. M. Jorge, C. F. Tachibana, and C. Barbosa, "Immunogenicity of Hepatitis B vaccine in preterm and full term infants vaccinated within the first week of life," Vaccine, vol. 20, no. 11-12, pp. 1557-1562, 2002.

[15] S. Bhave, S. Bhise, S. C. Chavan, et al., "Hepatitis B vaccination in premature and low birth weight (LBW) babies," Indian Pediatrics, vol. 39, no. 7, pp. 625-631, 2002.

[16] G. A. Losonsky, S. S. Wasserman, I. Stephens, et al., "Hepatitis $B$ vaccination of premature infants: a reassessment of current recommendations for delayed immunization," Pediatrics, vol. 103, no. 2, p. E14, 1999.

[17] N. K. Arora, S. Ganguly, S. N. Agadi, et al., "Hepatitis B immunization in low birthweight infants: do they need an additional dose?" Acta Paediatrica, vol. 91, no. 9, pp. 995-1001, 2002.

[18] N. Linder, R. Handsher, B. German, et al., "Controlled trial of immune response of preterm infants to recombinant hepatitis B and inactivated poliovirus vaccines administered simultaneously shorly after birth," Archives of Disease in Childhood: Fetal and Neonatal Edition, vol. 83, pp. F24-F27, 2000.

[19] O. Blondheim, D. Bader, M. Abend, et al., "Immunogenicity of hepatitis B vaccine in preterm infants," Archives of Disease in Childhood: Fetal and Neonatal Edition, vol. 79, no. 3, pp. F206-F208, 1998.

[20] A. Sood, D. Singh, S. Mehta, V. Midha, and R. Kumar, "Response to hepatitis B vaccine in preterm babies," Indian Journal of Gastroenterology, vol. 21, no. 2, pp. 52-54, 2002.

[21] G. Chirico, C. Belloni, A. Gasparoni, et al., "Hepatitis B immunization in infants of hepatitis B surface antigennegative mothers," Pediatrics, vol. 92, no. 5, pp. 717-719, 1993.

[22] M. Golewioska, D. Kardas-Sobantka, D. Chelbna-Sokol, and W. Sabanty, "Hepatitis B vaccination in preterm infants," European Journal of Pediatrics, vol. 158, no. 4, pp. 293-297, 1999.

[23] S. Chawareewong, A. Jirapongsa, and K. Lokaphadhana, "Immune response to hepatitis B vaccine in premature neonates," Southeast Asian Journal of Tropical Medicine and Public Health, vol. 22, no. 1, pp. 39-40, 1991.

[24] F.-Y. Huang, P.-I. Lee, C.-Y. Lee, L.-M. Huang, L.-Y. Chang, and S.-C. Liu, "Hepatitis B vaccination in preterm infants," Archives of Disease in Childhood: Fetal and Neonatal Edition, vol. 77, no. 2, pp. F135-F138, 1997.

[25] D. J. West, "Clinical experience with hepatitis B vaccines," American Journal of Infection Control, vol. 17, no. 3, pp. 172180, 1989.

[26] S. C. Kim, E. K. Chung, R. L. Hodinka, et al., "Immunogenicity of hepatitis B vaccine in preterm infants," Pediatrics, vol. 99, no. 4, pp. 534-536, 1997.

[27] K. Kesler, J. Nasenbeny, R. Wainwright, B. Mcmahon, and L. Bulkow, "Immune responses of prematurely born infants to hepatitis B vaccination: results through three years of age," Pediatric Infectious Disease Journal, vol. 17, no. 2, pp. 116-119, 1998.

[28] Z. Nejedlá, "The development of immunological factors in infants with hyperbilirubinemia," Pediatrics, vol. 45, no. 1, pp. 102-104, 1970.

[29] A. Ballesteros-Trujillo, A. Vargas-Origel, T. Alvarez-Muñoz, and C. Aldana-Valenzuela, "Response to hepatitis B vaccine 
in preterm infants: four-dose Schedule," American Journal of Perinatology, vol. 18, no. 7, pp. 379-385, 2001.

[30] S. Sanpavat, Y. Poovorawan, S. Chittinand, S. Bhongsvej, and P. Thaithumyanon, "Immunogenicity of hepatitis B vaccine in premature infants," The Southeast Asian Journal of Tropical Medicine and Public Health, vol. 25, no. 1, pp. 93-95, 1994.

[31] C.-A. Siegrist, "Why are boosters no longer necessary for protection against hepatitis B?" Revue du Praticien, vol. 54, no. 5, pp. 509-511, 2004.

[32] J. E. Banatvala and P. van Damme, "Hepatitis B vaccine-do we need boosters?" Journal of Viral Hepatitis, vol. 10, no. 1, pp. $1-6,2003$.

[33] A. R. Zanetti, A. Mariano, L. Romano, et al., "Long-term immunogenicity of hepatitis B vaccination and policy for booster: an Italian multicentre study," The Lancet, vol. 366, no. 9494, pp. 1379-1384, 2005.

[34] D.-S. Chen, "Long-term protection of hepatitis B vaccine: lessons from Alaskan experience after 15 years," Annals of Internal Medicine, vol. 142, no. 5, pp. 384-385, 2005.

[35] N. Linder, T. H. Vishne, E. Levin, et al., "Hepatitis B vaccination: long-term follow-up of the immune response of preterm infants and comparison of two vaccination protocols," Infection, vol. 30, no. 3, pp. 136-139, 2002.

[36] E. H. Boxall, J. A. Sira, N. El-Shuhkri, and D. A. Kelly, "Longterm persistence of immunity to hepatitis B after vaccination during infancy in a country where endemicity is low," Journal of Infectious Diseases, vol. 190, no. 7, pp. 1264-1269, 2004. 


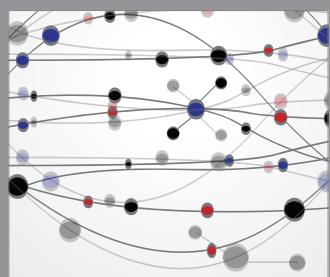

The Scientific World Journal
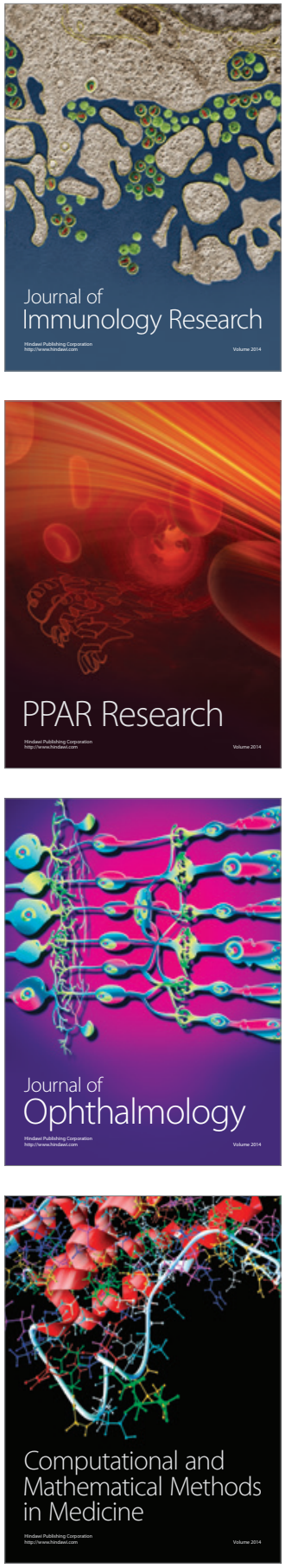

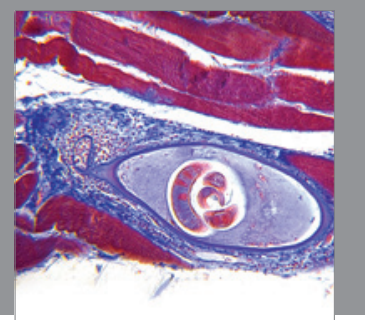

Gastroenterology

Research and Practice
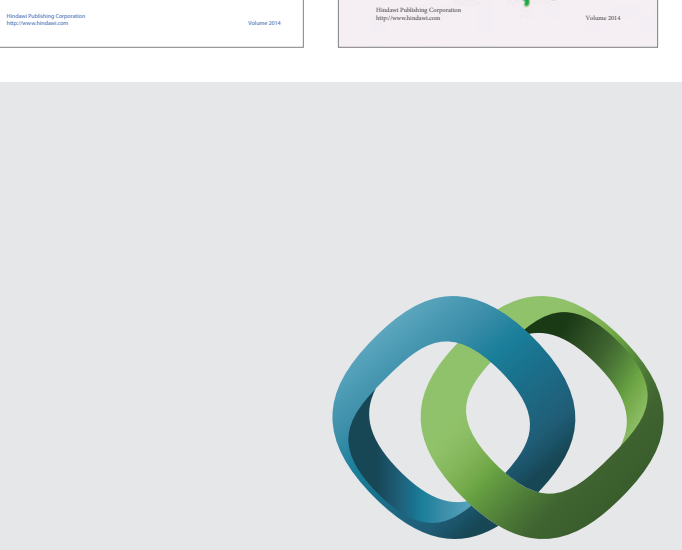

\section{Hindawi}

Submit your manuscripts at

http://www.hindawi.com
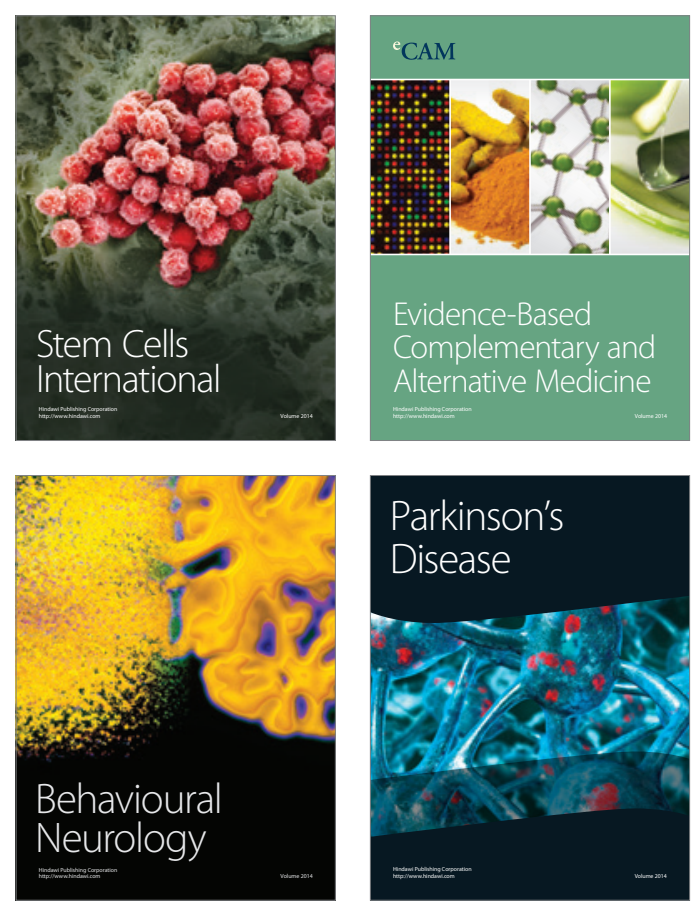

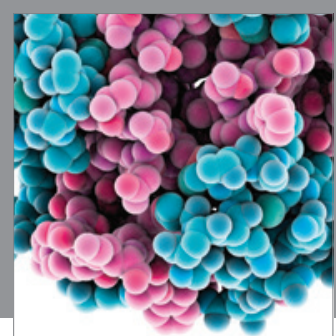

Journal of
Diabetes Research

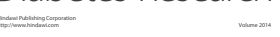

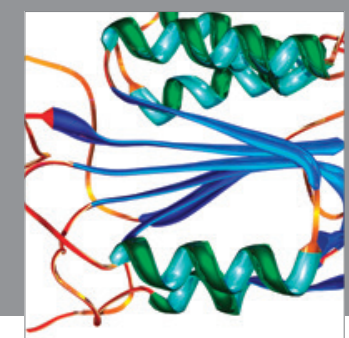

Disease Markers
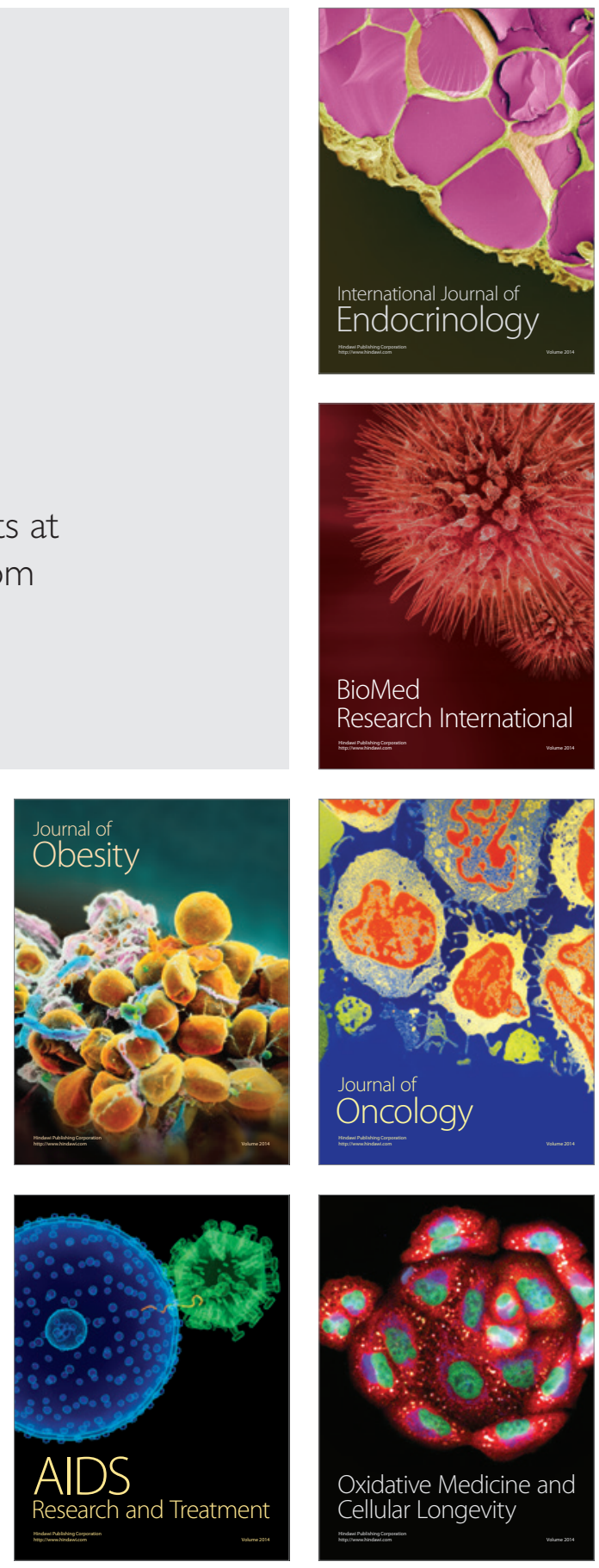